\title{
FLUTUAÇÃO POPULACIONAL E ANÁLISE FAUNÍSTICA DE LEPIDÓPTEROS DESFOLHADORES NA CULTURA DO AMENDOIM
}

\author{
José Ricardo Lima Pinto ${ }^{1}$ e Odair Aparecido Fernandes ${ }^{2}$ \\ ${ }^{1}$ Doutorando em Agronomia (Entomologia Agrícola), FCAV/UNESP, Jaboticabal, SP; ${ }^{2}$ Docente da \\ FCAV/UNESP, Jaboticabal, SP
}

RESUMO: O presente estudo teve como objetivo determinar a flutuação populacional e caracterizar os parâmetros faunísticos das principais espécies de lepidópteros desfolhadores que ocorrem na cultura do amendoim no estado de São Paulo. Para tanto, o levantamento populacional foi realizado em cultivo comercial de amendoim, na safra 2017/2018. A amostragem das lagartas foi realizada a cada 34 dias no período de 15 a 96 dias após a emergência (DAE) das plantas. O pico populacional de lagartas foi observado durante o estádio de desenvolvimento R6-R7. Ainda, observou-se que os principais lepidópteros desfolhadores na cultura do amendoim foram Stegasta bosqueella, Spodoptera cosmioides, Spodoptera albula, Anticarsia gemmatalis, Chrysodeixis includens, sendo que $S$. bosqueella foi a mais abundante $(71,68 \%)$ e mais constante $(95,65 \%)$, seguido de indivíduos pertencentes ao gênero Spodoptera. Essas informações permitem inferir que $S$. bosquella destaca-se como importante praga desfolhadora na cultura do amendoim. Além disso, a presença de espécies do gênero Spodoptera deve ser considerada nos planos de amostragem e tomada de decisão de controle.

Palavras-Chave: Arachis hypogaea L., monitoramento de pragas, manejo integrado de pragas.

\section{INTRODUÇÃO}

O Estado de São Paulo é responsável por cerca de $90 \%$ da produção brasileira de amendoim. O plantio geralmente é realizado entre os meses de setembro e outubro, prioritariamente em áreas de reforma de canavial (CONAB, 2018). Entre os diversos fatores limitantes à sustentabilidade da produção de amendoim, destacam-se as aplicações sucessivas de defensivos químicos utilizadas como medida de controle dos insetos-praga e fitopatógenos, que normalmente é baseada em pulverizações quinzenais.

A lagarta-do-pescoço-vermelho, Stegasta bosqueella (Chambers) (Lepidoptera: Gelechiidae), dentre os desfolhadores, é considerada uma das principais pragas da cultura do amendoim (BOIÇA JUNIOR et al., 2011). Outros lepidópteros desfolhadores podem ocorrer, mas tem sido considerados pragas de importância secundária. Entretanto, surtos populacionais dessas pragas podem ocorrer e comprometer a produção, conforme relatado na região da Alta Paulista (TEIXEIRA et al., 2001). Não obstante, em virtude das lagartas, principalmente de $S$. bosqueella, possuírem o hábito de se alojarem 


\section{Encontro Sobre a Cultura do Amendoim \\ 15 a 17 de agosto de 2019 na Estação de Eventos Cora Coralina e FCAV/UNESP, Jaboticabal-SP}

no interior dos folíolos fechados das plantas de amendoim, a amostragem torna-se extremamente laboriosa (ALMEIDA, 2015), reduzindo provavelmente a sua adoção pelos produtores.

Para o estabelecimento de um programa de Manejo Integrado de Pragas (MIP), informações sobre as espécies que ocorrem nos cultivos e sua abundância são essenciais afim de se priorizar o tipo de praga a ser controlada, estabelecer o momento ideal para tomada de decisão e evitar aumento dos custos de produção decorrente de aplicações desnecessárias para o controle desses insetos (PEDIGO; RICE, 2014). Como há escassez de estudos sobre a dinâmica de lepidópteros desfolhadores em amendoim, objetivou-se com o presente trabalho determinar a flutuação populacional de lepidópteros pragas e caracterizar abundância dessas espécies em lavouras comerciais de amendoim.

\section{MATERIAL E MÉTODOS}

O estudo foi conduzido em lavoura comercial de 6 ha, localizada no Sítio Bela Vista (21.43016893S e -48.60981799W), Taquaritinga, SP, Brasil, durante a safra 2017 /2018 com o cultivar IAC 503. O plantio e todos os tratos culturais foram realizados de acordo com os padrões adotados pelos produtores da região de Jaboticabal, SP, com restrição apenas para aplicação de produtos visando o controle de lagartas (não houve aplicação desses produtos). Para o controle do tripes do prateamento (E. flavens), as aplicações foram realizadas utilizando exclusivamente o inseticida thiamethoxan (Actara $250 \mathrm{WG}$, Syngenta), que não possui ação lagarticida.

O levantamento populacional de lepidópteros foi realizado a cada 3-4 dias, com início a partir de 15 dias após a emergência (DAE) das plantas e se estendeu até 96 DAE. Para tanto, a área de estudo foi dividida em seis parcelas de 1 ha cada e em cada parcela foram avaliados dez pontos aleatórios. O ponto de amostragem foi representado por três plantas em sequência na linha de cultivo. Realizou-se a coleta de lagartas desfolhadoras em quatro folíolos fechados de cada planta do ponto. Todas as lagartas coletadas foram conduzidas ao Laboratório de Ecologia Aplicada, FCAV/ UNESP, Jaboticabal, SP, onde foram contabilizadas e identificadas.

A flutuação populacional das espécies de lepidópteros foi baseada na média dos indivíduos capturados em 30 plantas (parcela) em cada data de amostragem. A análise faunística (frequência e constância) das espécies de imaturos foi realizada com base na metodologia proposta por Silveira Neto et al. (1976).

\section{RESULTADOS E DISCUSSÃO}

Os lepidópteros desfolhadores que ocorreram na cultura do amendoim foram: S. bosqueella, Spodoptera spp., Chrysodeixis includens (Walker) (Lepidoptera, Noctuidae), Anticarsia gemmatalis Hübner (Lepidoptera, Erebidae) e outros imaturos de lepidópteros cuja identificação não foi obtida (Tabela 1). A espécie $S$. bosqueella foi a mais abundante, seguida de espécies pertencentes ao gênero 


\section{Encontro Sobre a Cultura do Amendoim \\ 15 a 17 de agosto de 2019 na Estação de Eventos Cora Coralina e FCAV/UNESP, Jaboticabal-SP}

Spodoptera, com destaque para Spodoptera cosmioides (Walker) e Spodoptera albula (Walker) (Lepidoptera: Noctuidae). Stegasta bosqueella já havia sido documentada como praga-chave da cultura do amendoim (BOIÇA JUNIOR et al., 2011). Todavia, estudos envolvendo as espécies de Spodoptera em amendoim envolveram exclusivamente avaliação da capacidade de alimentação em condições de laboratório (CAMPOS et al., 2010; BOIÇA JUNIOR et al., 2011, 2013). Desse modo, este trabalho confirma a ocorrência dessas espécies em campo como desfolhadores e indica que elas devem ser consideradas em programas de MIP-Amendoim no estado de São Paulo.

Dentre as lagartas desfolhadoras, S. bosqueella (71,68\%) e Spodoptera spp. (14,36\%) foram as espécies mais frequentes em campo (Tabela 1). Foram realizadas um total de 23 amostragens, sendo que $S$. bosqueella, Spodoptera spp. e outros lepidópteros estavam presentes em 95,65, 73,91 e 65,21\% delas, respectivamente. Dessa forma, estas espécies podem ser caracterizadas como espécies constantes. Já A. gemmatalis $(13,04 \%)$ e C. includens $(17,39 \%)$ podem ser caracterizadas como espécies acessórias (Tabela 1). O fato de uma espécie ser constante ou acessória está relacionado com a sua capacidade de aproveitamento dos recursos durante o ano, sendo que aquelas que são constantes estão normalmente associadas a populações abundantes (SCHOWALTER, 2016).

Ainda, além da presença de $S$. bosqueella, a ocorrência de populações elevadas de indivíduos pertencentes ao gênero Spodoptera em cultivos de amendoim em diversas localidades foi previamente documentada e merecem atenção. Nos Estados Unidos, por exemplo, foram observadas infestações elevadas de Spodoptera exigua (Hübner), Spodoptera omithogalli (Guenée), Spodoptera litura (Fab.) e Spodoptera frugiperda (J.E. Smith) (Lepidoptera: Noctuidae) (WALL; BERBERET, 1975; KHARBOUTLI; MACK, 1993; NIGUDE, 2018). Na Índia, a espécie mais prejudicial a cultura do amendoim é S. litura (TIWARI et al., 2008). A presença de indivíduos do gênero Spodoptera na cultura sugere que, mesmo com o atual status de praga secundária, surtos podem ocorrer.

Tabela 1. Análise faunística de espécies de lepidópteros-praga coletadas em amendoim, Taquaritinga, SP, safra 2017 /2018.

\begin{tabular}{lcccc}
\hline Espécies & N & $\begin{array}{c}\text { Amostras com a } \\
\text { presença da espécie }\end{array}$ & Frequência & Constância \\
\hline S. bosqueella & 529 & 22 & 71,68 & $95,65 \mathrm{~W}$ \\
Spodoptera spp. & 106 & 17 & 14,36 & $73,91 \mathrm{~W}$ \\
A. gemmatalis & 4 & 3 & 0,54 & $13,04 \mathrm{Z}$ \\
C. includens & 19 & 4 & 2,57 & $17,39 \mathrm{Z}$ \\
Outras & 80 & 15 & 10,84 & $65,21 \mathrm{~W}$ \\
\hline
\end{tabular}

$\mathrm{N}=$ Total de fêmeas coletas; $\mathrm{W}=$ constante, $\mathrm{Y}=$ acessória, $\mathrm{Z}=$ acidental 


\section{Encontro Sobre a Cultura do Amendoim \\ 15 a 17 de agosto de 2019 na Estação de Eventos Cora Coralina e FCAV/UNESP, Jaboticabal-SP}

Foi constatado um baixo número de A. gemmatalis e C. includens ao longo das datas de amostragem (Figura 1). Por outro lado, populações de S. bosqueella e Spodoptera spp. foram coletadas durante praticamente todo o período de cultivo, sendo observado aumento na abundância dessas espécies a partir de 70 DAE. Os picos populacionais de S. bosquella e Spodoptera spp. ocorreram aos 93 e 80 DAE, respectivamente, quando as plantas de amendoim se encontravam nos estádios de desenvolvimento R6-R7 (Figura 1). Nestes estádios há maior disponibilidade de folíolos fechados. Esta maior oferta de recurso alimentar é um fator positivo que favorece aumento populacional de herbívoros na cultura do amendoim (CASTRO et al., 1972). A correta identificação das pragas, bem como, o conhecimento sobre a dinâmica populacional é importante no planejamento e tomada de decisão em programas de MIP. A destacada presença de espécies de Spodoptera exige que estudos sejam realizados para mensurar o potencial de alimentação e avaliar o impacto desses desfolhadores sobre a produção de amendoim.

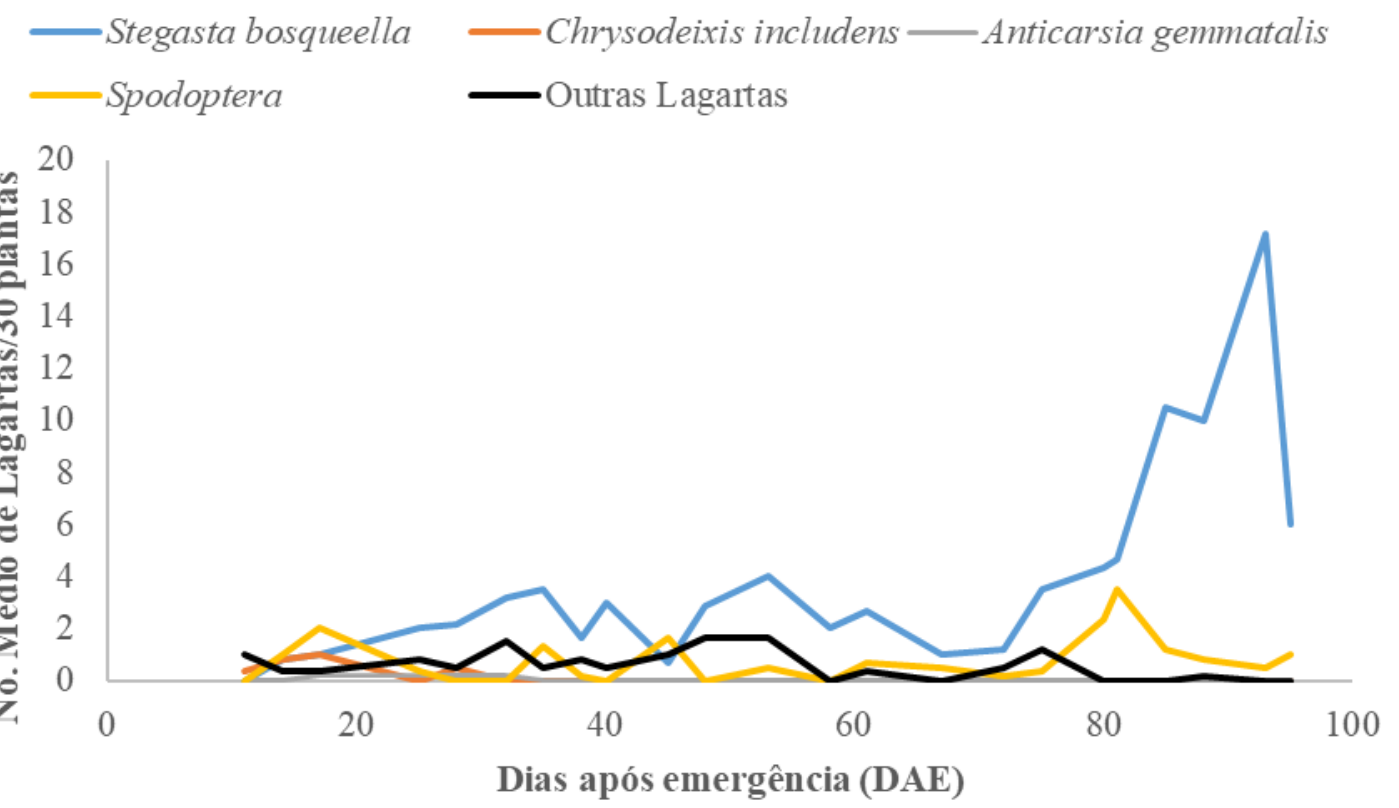

Figura 1. Flutuação populacional de espécies de lepidópteros desfolhadores em amendoim, Taquaritinga, SP, safra 2017 /2018.

\section{CONCLUSÕES}

Os principais lepidópteros desfolhadores que ocorrem na cultura do amendoim são $S$. bosqueella, S. cosmioides, S. albula., A. gemmatalis e C. includens

O pico populacional de lagartas ocorre durante o estádio de desenvolvimento R6-R7.

Stegasta bosqueella e Spodoptera spp. são as espécies mais abundantes na cultura do amendoim. 


\section{Encontro Sobre a Cultura do Amendoim \\ 15 a 17 de agosto de 2019 na Estação de Eventos Cora Coralina e FCAV/UNESP, Jaboticabal-SP}

\section{AGRADECIMENTOS}

Os autores prestam seus agradecimentos a Coordenação de Aperfeiçoamento de Pessoal de Nível Superior (CAPES), processo 001 pela concessão da bolsa de estudos; À Arysta LifeScience (UPL Brasil) pelo suporte financeiro; À COPLANA - Cooperativa Agroindustrial pelo apoio nos ensaios realizados em campo.

\section{REFERÊNCIAS}

BOIÇA JUNIOR, A.L.; FERRAREZI, R.; RODRIGUES, N.E.L.; SOUZA, B.H.S.; BOTTEGA, D.B.; SILVA, A.G. Resistência de cultivares de amendoim de hábitos de crescimento ereto e rasteiro a Spodoptera cosmioides em laboratório. Revista Agro@mbiente On-line, 7: 80-88, 2013.

BOIÇA JUNIOR, A.L; RIBEIRO, Z.A; CAMPOS, A.P; CHAGAS FILHO, N.R. Técnica de criação e parâmetros biológicos de Stegasta bosquella em amendoim. Revista Caatinga, 24: 192-196, 2011.

CAMPOS, A.P.; BOIÇA JUNIOR, A.L.; RIBEIRO, Z.A. Não preferência para oviposição e alimentação de Spodoptera frugiperda (JE Smith, 1797) (Lepidoptera: Noctuidae) por cultivares de amendoim. Arquivos do Instituto Biológico, 77: 251-258, 2010.

CASTRO, P.R.C; PITELLI, R.A.; PASSILONGO, R.L. Variações na ocorrência de algumas pragas do amendoinzeiro relacionadas com o desenvolvimento da cultura. Anais da Sociedade Entomológica do Brasil, v. 1, n. 1, 1972.

CONAB (Companhia Nacional de Abastecimento). Acompanhamento da safra brasileira: grãos. Safra 2017/2018. Décimo primeiro levantamento, agosto 2018. Monitoramento agrícola Safra 2018, v.5, n.11, p.1 - 148, 2018. Disponível em http://www.conab.gov.br>.

KHARBOUTLI, M.S; MACK, T.P. Comparison of three methods for sampling arthropod pests and their natural enemies in peanut fields. Journal of Economic Entomology, 86: 1802-181, 1993.

NIGUDE, V.K.; PATIL, S.A.; MOHITE, P.B.; BAGADE, A.S. Seasonal incidence of tobacco leaf eating caterpillar and leaf miner of groundnut (Arachis hypogaea L.). International Journal of Current Microbiology and Applied Sciences, 7: 562-565, 2018.

PEDIGO, L.P; RICE, M.E. Entomology and pest management. New Jersey, Pearson Prentice Hall, $784 \mathrm{p}, 2014$.

SCHOWALTER, T.D. Insect ecology: an ecosystem approach. Academic Press, 2016.

SILVEIRA NETO, S.; NAKANO, O.; BARBIN, D.; VILLA NOVA, N.A. Manual de ecologia dos insetos. Piracicaba: Ceres 419p, 1976.

TEIXEIRA, E.P.; NOVO, J.P.S.; STEIN, C.P.; GODOY, I.J. Primeiro registro da ocorrência de Spodoptera albula (Walker) (Lepidoptera: Noctuidae) atacando amendoim (Arachis hypogaea L.) no estado de São Paulo. Neotropical Entomology, v. 30, n. 4, p. 723-724, 2001. 
XVI Encontro Sobre a Cultura do Amendoim

15 a 17 de agosto de 2019 na Estação de Eventos Cora Coralina e FCAV/UNESP, Jaboticabal-SP

TIWARI, S.; MISHRA, D.K.; SINGH, A.; SINGH, P.K.; TULI, R. Expression of a synthetic cry1EC gene for resistance against Spodoptera litura in transgenic peanut (Arachis hypogaea L.). Plant Cell Reports, 27: 1017-1025, 2008.

WALL, R.; BERBERET R.C. Parasitoids associated with lepidopterous pests on peanuts; Oklahoma fauna. Environmental Entomology, 4: 877-882, 1975. 